\title{
THE CONSTRUCTAL EVOLUTION OF SPORTS WITH THROWING MOTION: BASEBALL, GOLF, HOCKEY AND BOXING
}

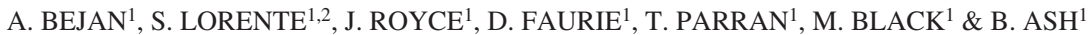 \\ ${ }^{1}$ Duke University, Department of Mechanical Engineering and Materials Science, Durham, NC 27708-0300, USA. \\ ${ }^{2}$ Université de Toulouse; UPS, INSA; LMDC (Laboratoire Matériaux et Durabilité des Constructions); \\ 135, avenue de Rangueil; F-31 077 Toulouse Cedex 04, France.
}

\begin{abstract}
Here we show that the trends in four sports are united by the evolutionary constructal design of all animal locomotion. The trend is toward greater efficiency in the falling-forward movement of the body, and this is why the evolution of the throwing motion unites team sports (baseball, hockey) with individual sports (golf, boxing, running and swimming). Records during the past 100 years indicate that in these sports the trend has been toward bigger and taller bodies, which possess greater speed of falling forward and throwing, greater force, and greater throwing distance. Equipment technology (golf balls, hockey sticks) has evolved in the same direction. In sum, the evolution of sports is in accord with the constructal law, and constitutes a "laboratory" for witnessing the evolution of biological design in our lifetime.

Keywords: Baseball, Boxing, Constructal Law, Golf, Hockey, Sports evolution, Throwing motion.
\end{abstract}

\section{WITNESSING EVOLUTION}

Design in nature evolves over time, and occurs in many forms that cover the entire spectrum of flow and movement, from physics to biology and social organization. The globe is a tapestry of flow systems with designs that facilitate movement everywhere. This unifying point of view is provided by the constructal law [1], which states that flow systems persist in time (they live) by morphing into configurations and rhythms that flow more easily, and provide greater access to their currents.

The theoretical steps made with the constructal law to account for animate, inanimate and engineered designs were reviewed most recently in Refs. [2-5]. A key step was the unification of animal locomotion design (flying, running, swimming) into a predictive theory of the rhythm of body movement that facilitates the flow of animal mass on the landscape: more mass moved to greater distances per unit of work (useful energy) spent. With the constructal law, the design of the flow of animal mass has the same origin as the design of the flow of water in river basins and vegetation $[6,7]$, and the design of the hierarchical movement of people and goods on the landscape [8].

The most basic scaling relations of animal movement were predicted in this manner [6]. They are summarized qualitatively by the statement that larger animals travel faster, undulate their bodies less frequently, exert greater forces, and spend less work per unit of animal mass moved to a specified horizontal distance. This is the design toward which the flow of animal mass evolved and converged in big history, even though the actual evolution of the design is not visible because of its extremely long time scale.

More recently, we used this theoretical approach to show how to witness in our life-time the evolution of the animal mass flow design. The method is to focus on the evolution of modern athletics. We selected one sport and observed the evolution of the measurements (size, performance) of a carefully defined population of athletes who pursue a single goal: speed. We demonstrated the method by focusing on speed running (100 $\mathrm{m}$ dash) and speed swimming (100 $\mathrm{m}$ freestyle), men and women, during the past one hundred years $[9,10]$. We found that the speed-size relation evolved in accord 
with the relation for all animal locomotion, and concluded that for greater and greater speeds the record breakers should be expected to be (in time) larger, taller and more slender.

In sum, the evolution of individual sports casts a new light on the phenomenon of animal evolution. The question that we explore in this paper is whether team sports also illustrate the evolution of design. Initially, we thought that team sports are not good visualization instruments because on a team the individual players pursue many objectives at the same time. Some of the objectives are shared by all the players, others differentiate between players. In this paper we show that team sports can also be used to visualize evolution. For this new addition to the constructal theory of sports evolution we chose the game of baseball. We then discover that the main design of this game-the throwing of mass - unites its evolution with other sports that rely on mass throwing: golf, hockey and boxing.

\section{BASEBALL}

The game of throwing a ball and hitting it with a wooden stick has a history as old as sheep herding. "Baseball" is the newest version of the pre Roman shepherd game that became "cricket" in the British Isles and "oina" in Romania. The most basic movement in the game is the throwing of a dense ball: the faster the throw the more successful the thrower, because the batter (the player with the stick) has less time to react and make contact with the approaching ball.

The throwing motion is that of a linkage consisting of the human body that falls forward and the ball that follows from behind and over the head of the thrower (Fig. 1). The entire linkage accelerates as it falls forward. This linkage and motion are similar to the mechanism of the trebuchet, which was a middle-aged weapon for throwing heavy stones against fortifications. The rope of the trebuchet is an invention that works because it improves the linkage provided by the human arm (see segments 1

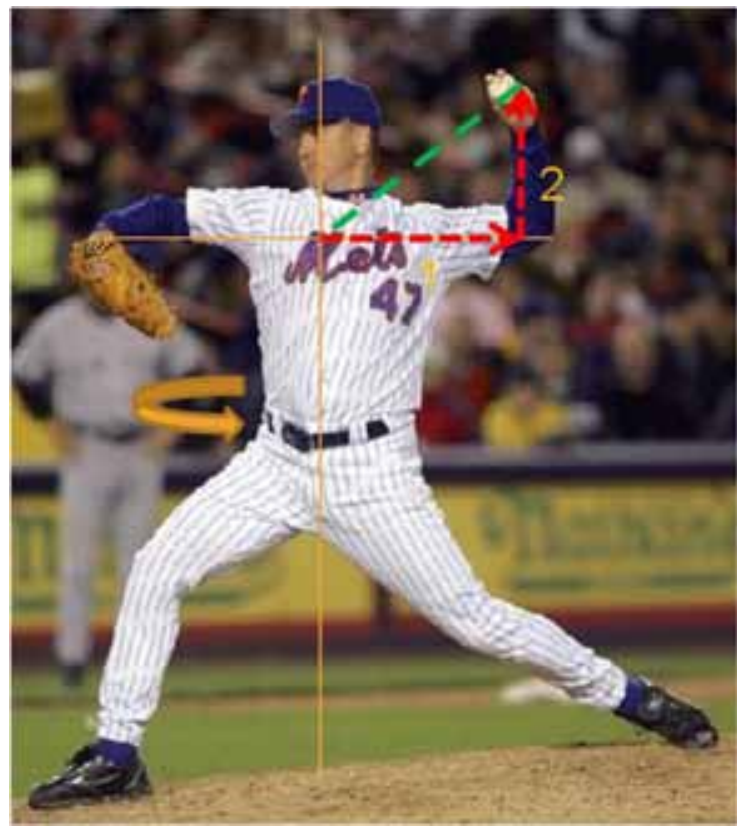

(a)

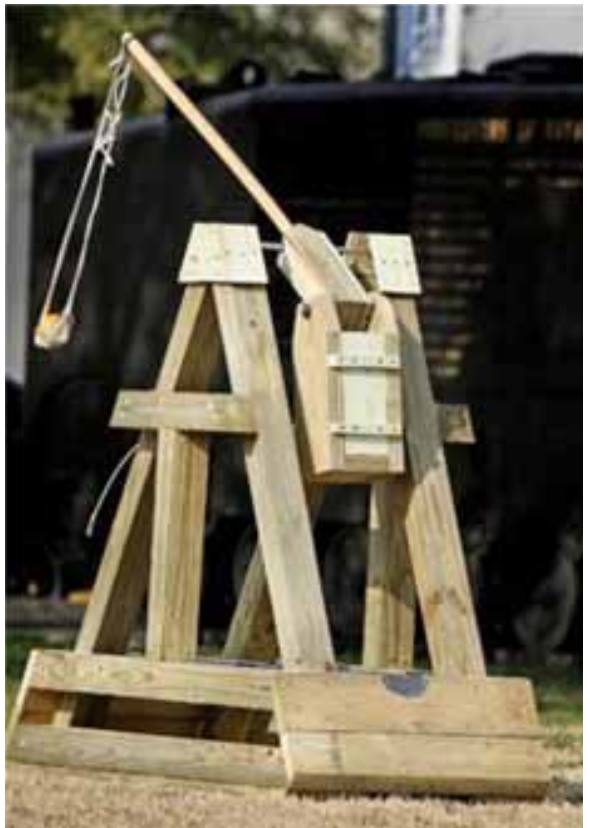

(b)

Figure 1: (a) The falling forward motion of the thrower. (b) The mechanism of the trebuchet. 
and 2 in Fig. 1). The improvement comes from the fact that the rope can be made longer, and the falling forward can be made faster by properly preloading the spring before it is released.

According to the constructal-law prediction of speeds in animals $[6,7]$ and speed running and swimming $[9,10]$, the greater speeds belong to bodies that are larger and taller. The same holds for the trebuchet, because the larger and taller machine is capable of throwing a larger mass farther. In the case of the human thrower, the height of the mechanism is the height of the ball that is accelerated overhead. This height scales with the size of the athlete, in this case, the shoulder height plus the arm length.

The expectation based on the constructal law is to find larger and taller athletes in sports that require greater throwing speed. This expectation is amply confirmed by the manner in which the game of baseball has evolved. Figure 2 shows the average heights of professional baseball players since 1960, and how these heights are distributed according to the position occupied by the players on the field $[11,12]$. To be counted in this compilation, the player had to play at least five games at this position.

The tallest are the players who must throw the fastest, namely the pitchers $(\mathrm{P})$. This evolutionary trend is evident and not surprising, because play begins with the pitch, and the spectators' attention is focused on the pitcher. Yet, there is more evolutionary design in Fig. 2, and it is subtle. The field players also rely on throwing speed, but not to the same degree. The decrease in heights from right to left in Fig. 2 is in accord with the need for throwing speed.

Most of the infield plays end with throws to first base. The objective of the throw is to make the ball arrive at first base (1B, Fig. 3) before the runner (who runs from $\mathrm{C}$ to $1 \mathrm{~B}$ ). This means that greater speed is needed from those who throw from farther away. The distance to first base (1B) decreases in the sequence: third base (3B), short stop (SS) and second base (2B). This is the same sequence in which the average heights of these groups of players decrease in Fig. 2.

Even faster throws are needed in order to catch the runner on the line between home plate $(\mathrm{C})$ and first base (1B), and on the lines connecting the bases. Although the catcher does make throws to 1B, the most frequent throws are from $\mathrm{C}$ to $2 \mathrm{~B}$, which is even at a greater distance than $1 \mathrm{~B}$. Some of the

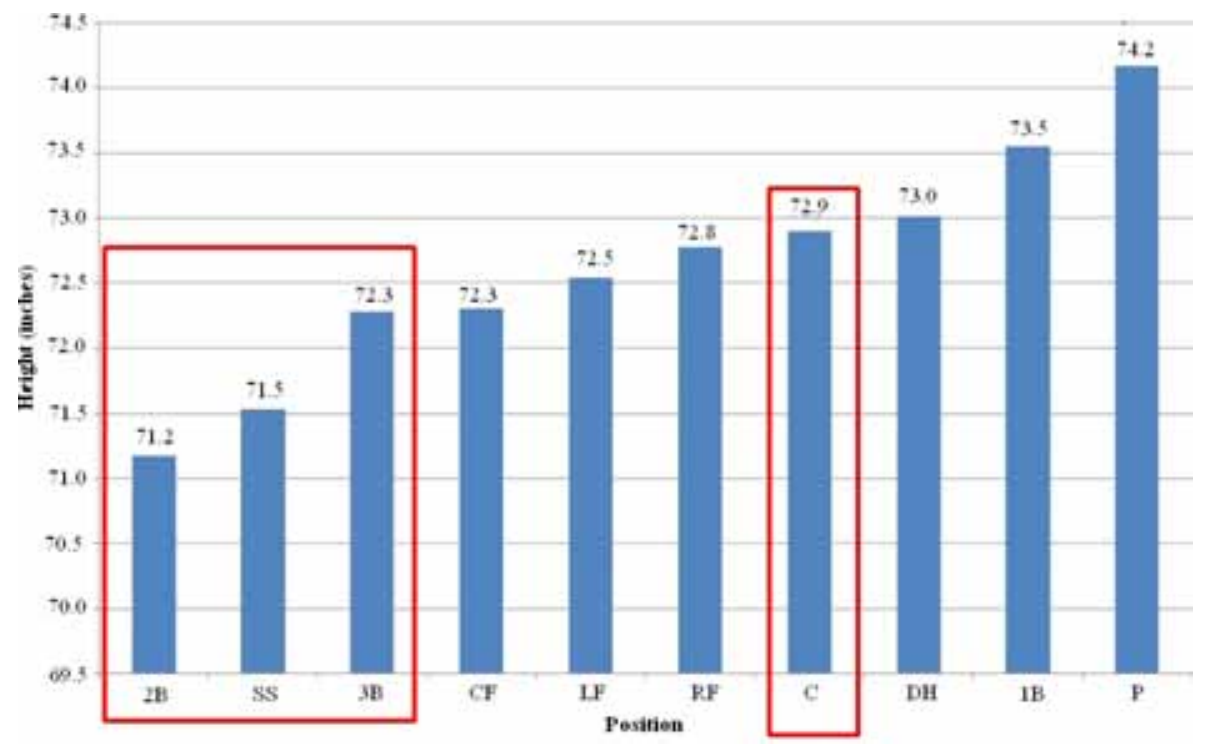

Figure 2: The average heights of professional baseball players since 1960 [11, 12]. 


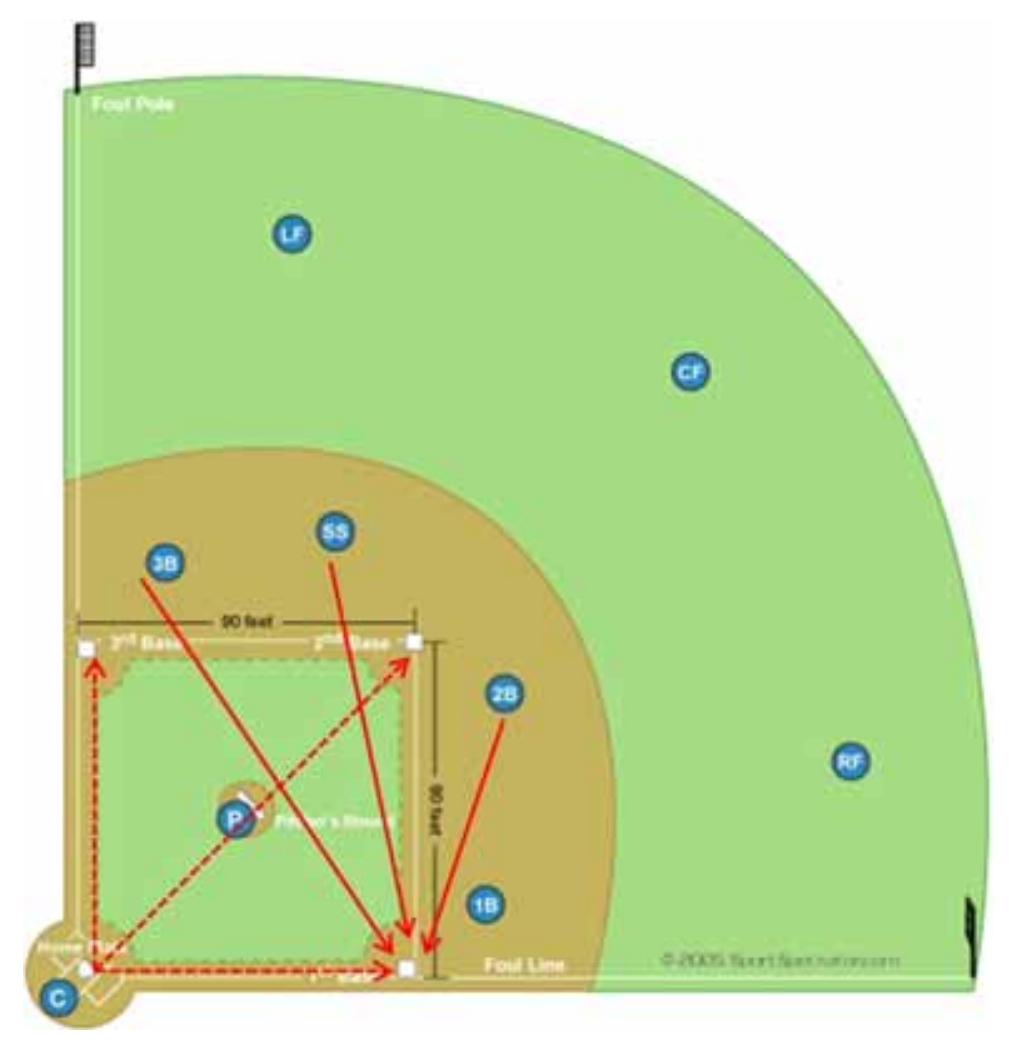

Figure 3: The most frequent throwing lanes in the infield [11, 12].

shorter throws are made by catchers on their knees (a position that rules out the power derived from their legs), and this means that the power is derived from the upper body. This gives an advantage to catchers with longer torsos and wing span, which usually correlate with greater overall height. First basemen need to be tall because they must be able to stretch farther off the base in order to make a wider range of catches. Their height is an advantage for catching the ball, rather than throwing the ball. The correlation between height and position $(\mathrm{C}, 1 \mathrm{~B})$ is confirmed by Fig. 2 .

Further support for these evolutionary features of the game is offered by Fig. 4. The average height of the pitchers active in one season has increased almost at constant rate during the past century. The two downturns in this trend were short lived and coincided with the two world wars, when the access of young men to the sport was curtailed. The upward trend in player heights is further confirmed by Fig. 5, which shows the heights of all the major league players (all positions) born between 1970 and 1985.

Even in a single year, the highest throwing speed correlates with height. Figure 6 shows the 20 fastest throws recorded in 2009 in the major leagues. The scatter is not the main feature of this graph. Important is the upper envelope of the cloud of data. The envelope has a positive slope, which confirms that the fastest throws correlate with the taller athletes. On average, players entering the games are larger (taller) athletes, because the game as a whole is about throwing speed and hitting power (or bat speed), which favors larger athletes.

Height $(\mathrm{H})$ is not the only measure of an athlete's size. Recorded in the annals of the game is also the athlete's body mass (M). These two measurements are sufficient for estimating the body shape 


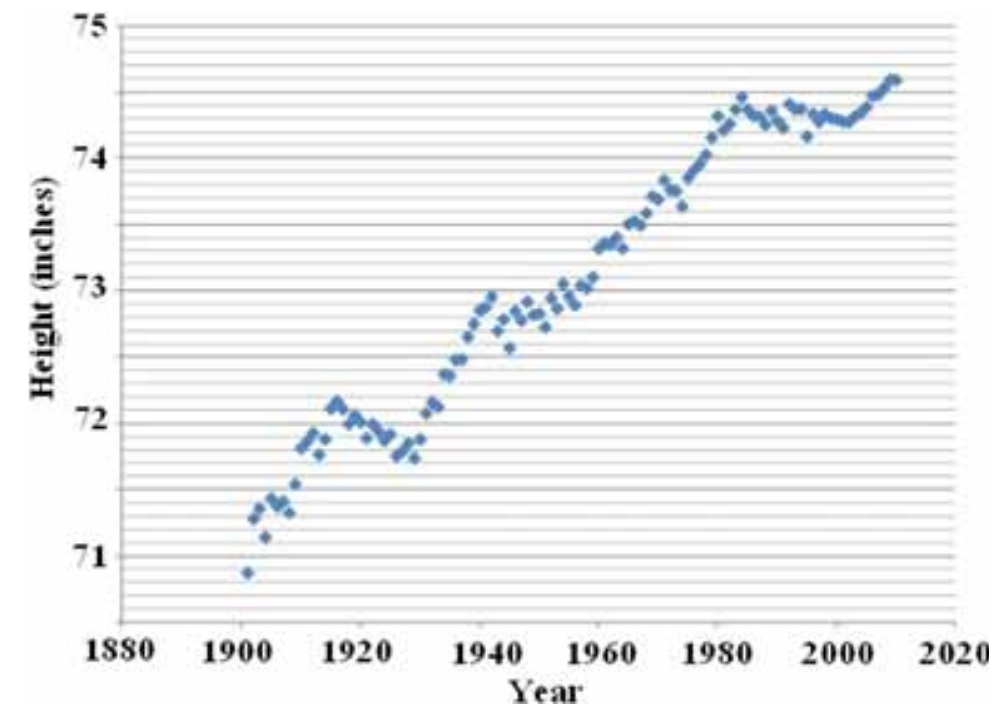

Figure 4: The season averaged height of pitchers by season since 1901 [11, 12].

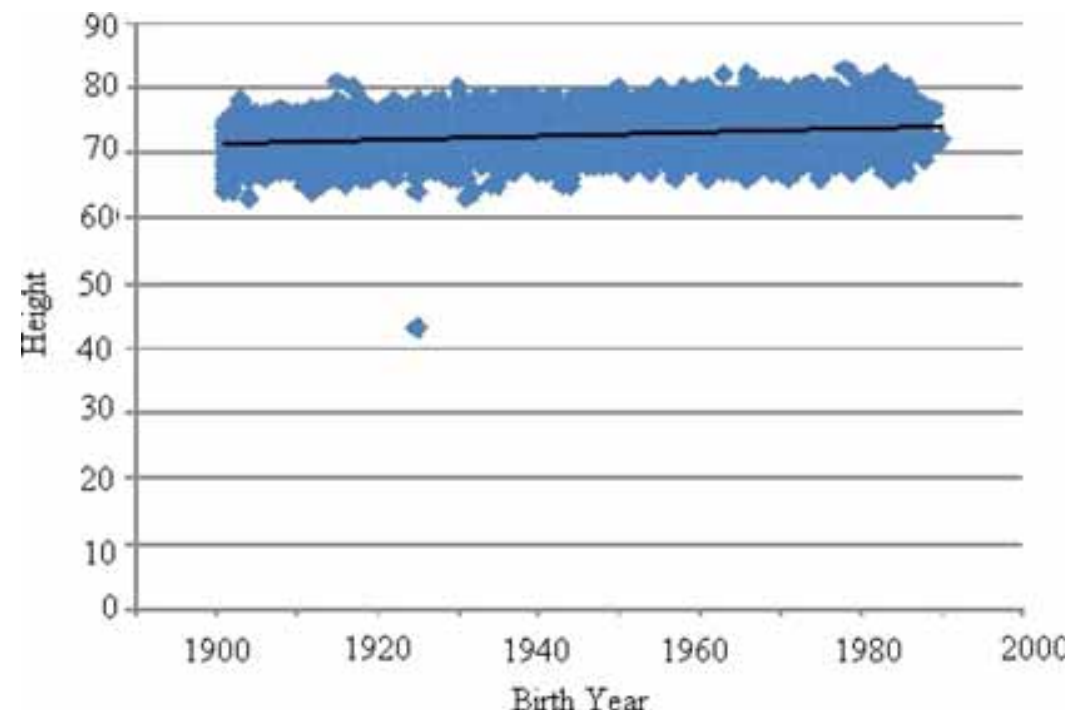

Figure 5: The heights of all the major leagues baseball players during the 20th century $[11,12]$.

(the slenderness), and, from the evolution of $\mathrm{H}$ and $\mathrm{M}$ in time follows the evolution of the body shape. The calculation of the body slenderness is based on modeling [9] the athlete's body as a cylinder of height $\mathrm{H}$ and diameter $\mathrm{D}$, such that the body mass is

$$
M=\rho \frac{\pi}{4} D^{2} H
$$

where the body density is on the order of $\rho \cong 10^{3} \mathrm{~kg} / \mathrm{m}^{3}$. The body slenderness ratio is defined as 


$$
\mathrm{S}=\frac{\mathrm{H}}{\mathrm{D}}
$$

where D is furnished by Eqn. (1) from the measured values of $\mathrm{H}$ and $\mathrm{M}$,

$$
\mathrm{D}=\left(\frac{4 \mathrm{M}}{\pi \rho \mathrm{H}}\right)^{1 / 2}
$$

Figure 7 shows how the slendernesses and heights line up for the players in the American League in 2011. The cloud of $(\mathrm{S}, \mathrm{H})$ data is slender, with a positive slope. This means that the taller athletes

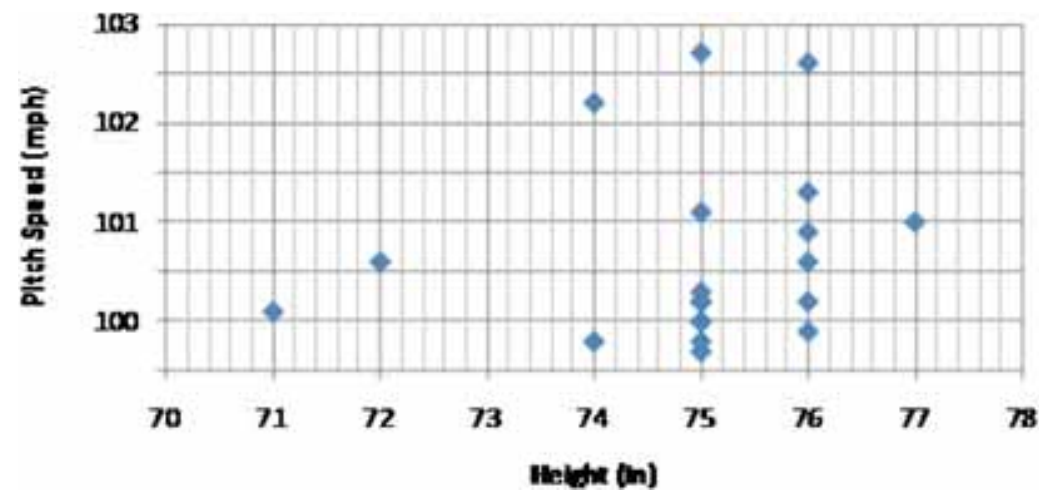

Figure 6: The 20 fastest pitches recorded in 2009, versus the heights of the pitchers [11].

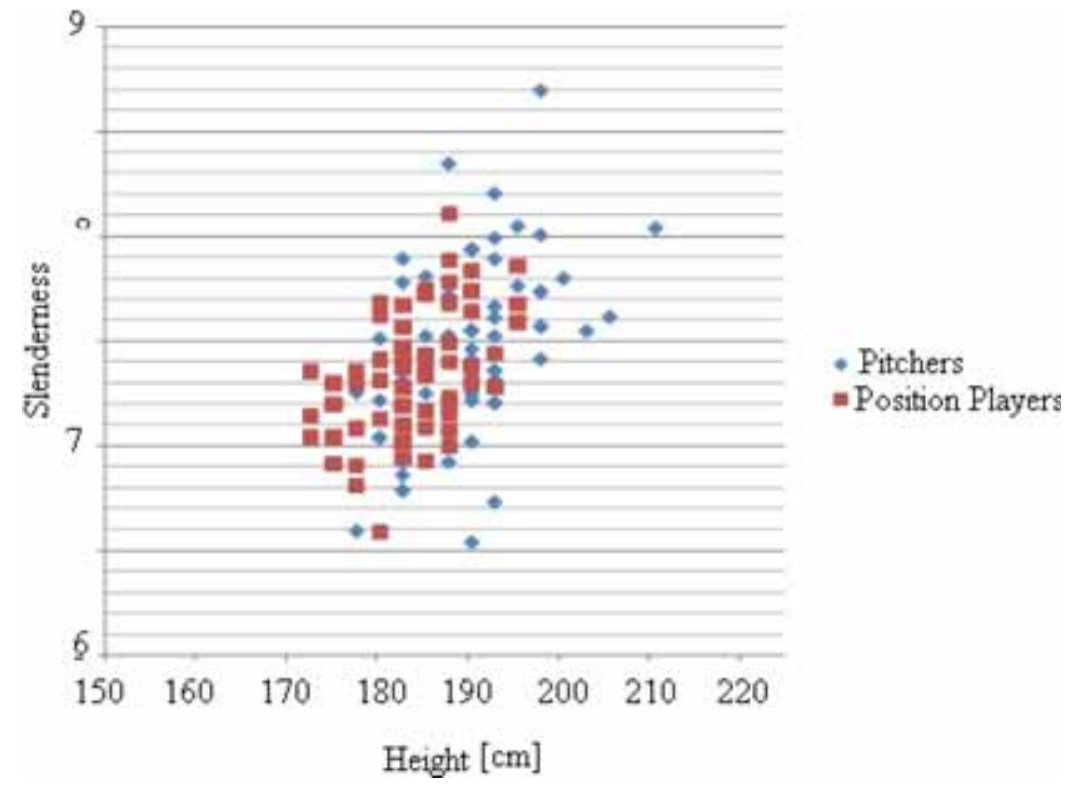

Figure 7: The slendernesses and heights of all the baseball players in the 2011 American League [12]. 
are also more slender. This characteristic holds for pitchers and field players. The data can also be organized to show that the trend of $\mathrm{S}$ versus $\mathrm{H}$ also holds for individual positions: pitchers, second basemen, and third basemen. Because heights trend upward over time (Figs 4 and 5), it means that the body slenderness also trends upward. The evolution of the slenderness of baseball players toward larger $\mathrm{S}$ values agrees with the trend exhibited by the $\mathrm{S}$ values of record holders in the $100 \mathrm{~m}$ sprint [9].

\section{GOLF}

The evolution of golf is also oriented toward greater speed. The taller and larger golfers are able to drive the ball further than the shorter and smaller golfers. Data on golfer driving distance, height, and weight were collected from Ref. [13], which has statistics posted from 1980 to the present. The height and weight for golfers near the top, middle, and bottom of average driving distance was taken from each player's profile for the years 1980, 1990, 2000, and 2010 (Table 1). The purpose of taking data from several different years was to see if a trend developed over time towards taller and larger players. The collected data were analyzed graphically and using linear regression.

The data for height versus driving distance can be seen in Fig. 8 and shows a definite upward trend. From 1980 to 2010 golfer driving distance has been steadily increasing; however the slope of the trend line has been decreasing, from 3.75 yards/inch in 1980 to 1.5 yards/inch in 2010. This shows that height currently plays a less important role in driving distance than it did in 1980, which could be due to improved technique or technology, because the average golfer height has remained the same at 71.25 inches. In 2010, the average golfer was over an inch taller than the average American, and the average golfer in the top 10 in driving distance each year was 2.5 inches taller than the average golfer in the bottom 10 of driving distance each year (Table 1). This shows that height plays a definite role in the success of an athlete in golf.

The data for body mass and driving distance show a similar trend, Table 1 . The increase in driving distance with mass is due to the fact that larger moving bodies are capable of exerting greater forces [6]. In 2010 the data for body mass versus driving distance showed a positive slope of 0.32 yards/ $\mathrm{lbm}$ (Fig. 9). The average body mass of golfers for the top 10 in driving distance is $18.51 \mathrm{bm}$ greater than the average weight for golfers in the bottom 10 in driving distance from year to year.

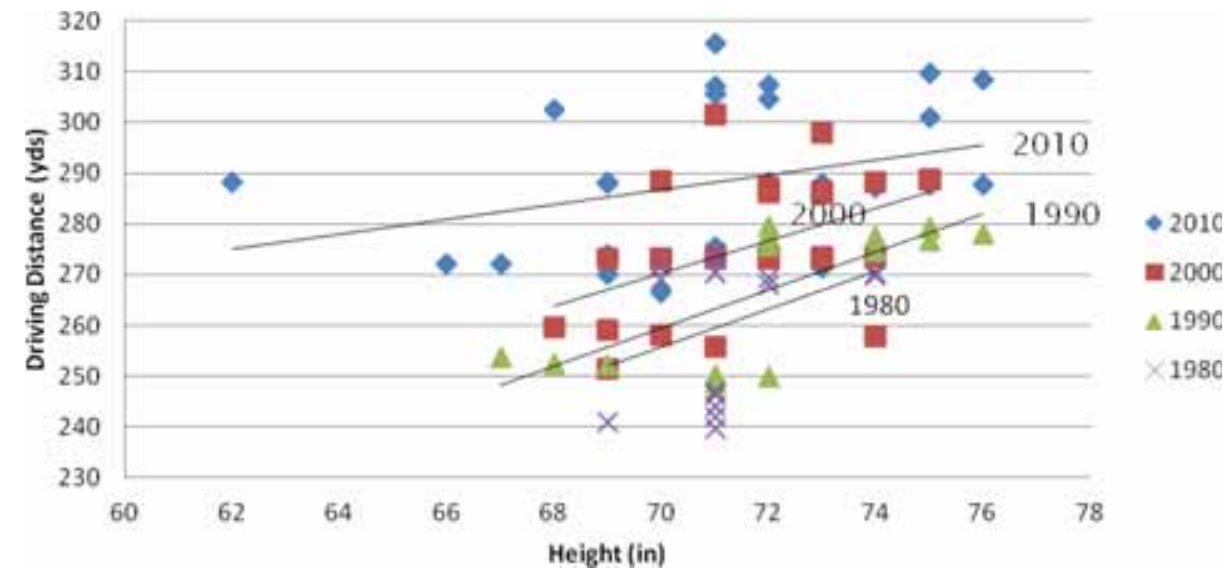

Figure 8: The evolution of player height versus driving distance in golf. 
Table 1: The average heights and masses of the top 10 and bottom 10 drivers in golf.

\begin{tabular}{cccccc}
\hline & \multicolumn{2}{c}{ Top 10 Drivers } & & \multicolumn{2}{c}{ Bottom 10 Drivers } \\
\cline { 2 - 3 } \cline { 5 - 5 } Year & Height (in) & Mass (lbm) & & Height (in) & Mass (lbm) \\
\hline 1980 & 71.6 & 191.5 & & 70.7 & 170.0 \\
1990 & 73.6 & 200.0 & 69.7 & 179.2 \\
2000 & 72.8 & 195.0 & 70.2 & 172.3 \\
2010 & 72.2 & 186.0 & 70.0 & 176.8 \\
\hline
\end{tabular}

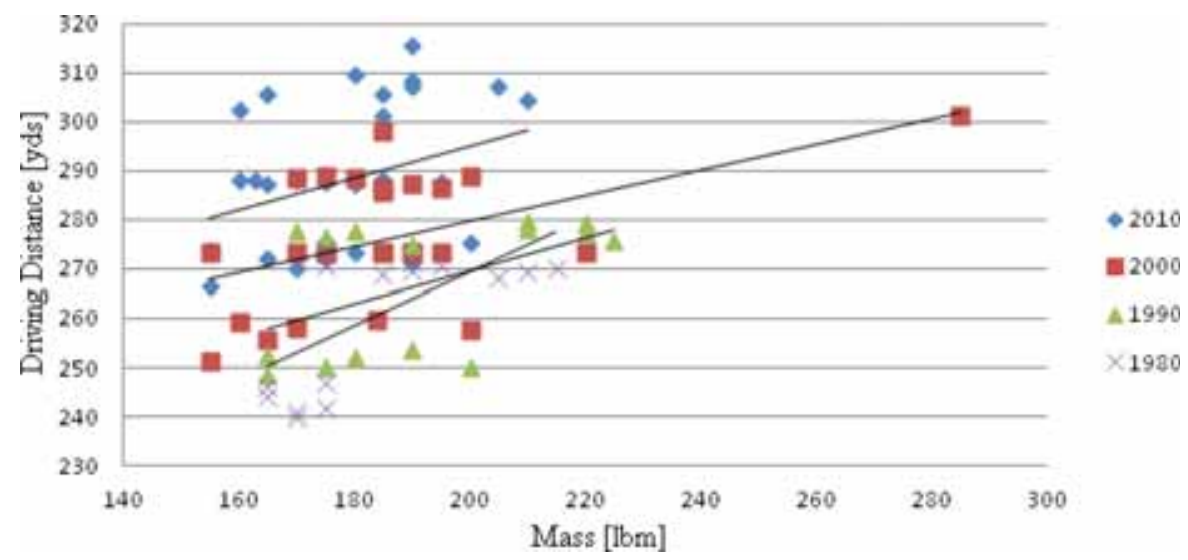

Figure 9: The average of player body mass versus driving distance in golf.

The average driving distance increased by 1 yard/year since 1980 to 2010, as shown in Fig. 10 . This increase shows large jumps that correlate with major innovations in driver technology. Right around 1980 is when the first all metal drivers were introduced and wooden drivers were phased out: the jump in driving distance from 1980 to 1985 correlates with the full switch to metal drivers on the tour. The jump during 1995-2000 corresponds with the introduction of larger lighter drivers made out of titanium rather than steel. The large jump during 2000-2005 corresponds to the introduction of graphite shafts, full $460 \mathrm{~cm}^{3}$ drivers, and new composite materials that are lighter and stronger than titanium. Over the past 30 years, driver technology has evolved toward better performing drivers that are larger and lighter than their predecessors.

The technology of the sport has also evolved toward greater speed, which means greater distance. The evolution of the golf ball affected the game most significantly. The first ball used was the Featherie Cube. The Featherie consisted of 3 pieces of stout leather stitched together and stuffed with either goose or chicken feathers. It was fragile and aerodynamically inefficient. This ball persisted for about four centuries before being replaced by the Gutta-Percha in 1848. The Gutta was made from the evaporated latex extracted from the Gutta-percha tree. They were made by heating the material to a moldable temperature, and hand rolling them into shape. The final product was a hard, non brittle, smooth-surfaced ball. The Gutta significantly increased the run distance of the golf ball, but players discovered that balls with nicked or unsmooth surfaces flew truer than the smooth Gutta. This gave way to the hand-hammered Gutta ball, which was made by hammering an even pattern 


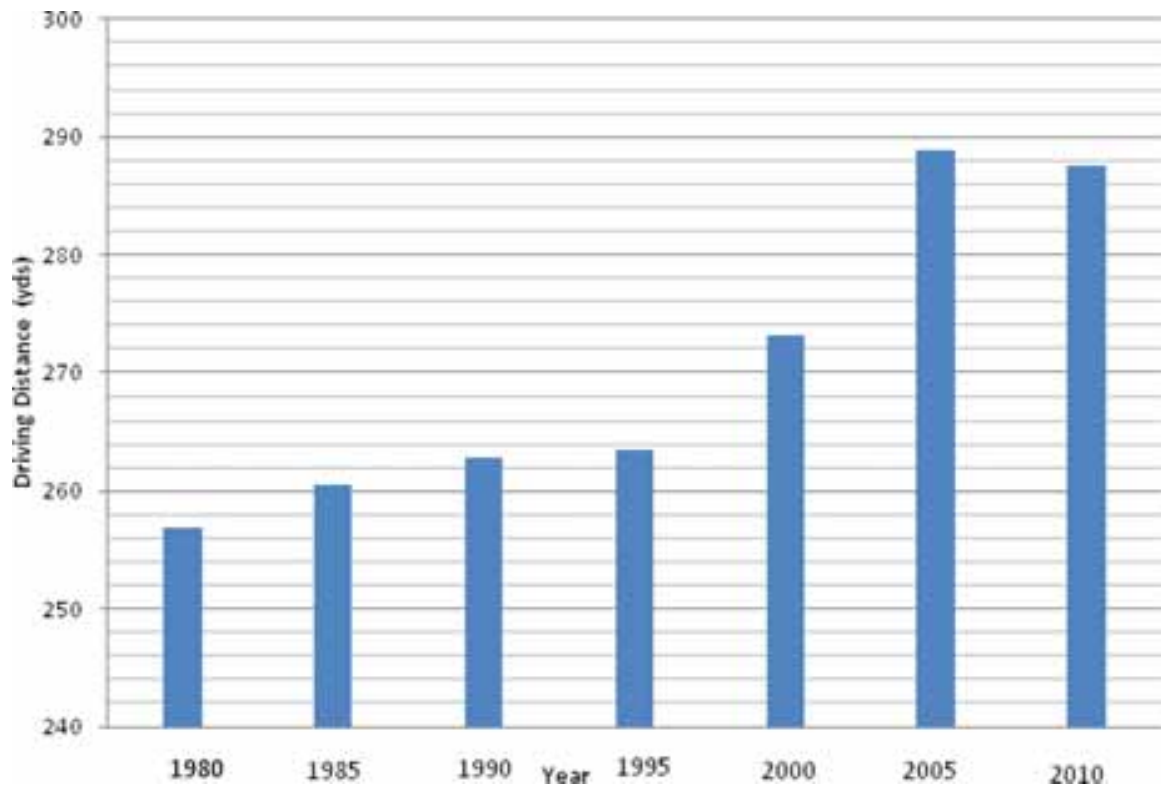

Figure 10: Golf: the average driving distance by year.

into the traditional Gutta ball with a sharp-edged hammer. It was discovered that highly detailed and symmetrical patterns were the best in improving the flight of the golf ball, and the most popular became the Bramble pattern. This pattern consisted of hundreds of small bumps coating the surface of the ball.

Over time, the material of the ball changed, and the rubber ball, called the Haskell, was introduced. This ball had a rubber core wound in rubber thread, but originally maintained the Bramble pattern on its exterior. This ball had a tremendous impact on the game, and was cause for concern among players. The ball was further improved with the introduction of the dimple pattern in 1908. This pattern is aerodynamically superior to all other patterns used at that time, and is still used in the modern golf ball. The golf ball today is a multi-component urethane elastomer ball first introduced as the Titleist ProV1 in 2000. The ball uses solid core technology which had been around for some time before. As shown in Fig. 11, solid core technology has had a significant impact on driving distance.

Golf clubs have also evolved substantially over several decades. Before the 1800s clubs were simply fashioned from whatever wood was available. Club shafts were commonly fabricated from woods such as ash or hickory, while club heads were made from relatively harder woods such as apple, beech, or pear. In these early days of the game, the idea of the club set had begun to take shape. The club set offered a greater variety of clubs which, in turn, offered a greater variety of shot types. In the 1800 s, irons were crafted by blacksmiths, and at this stage they were very crude and heavy, providing subpar accuracy, control, distance, and swing speed. The forging process, developed in the late 1800s, made possible the series production of more precisely shaped irons. In the 1900s, the transition from smooth faced irons to groove faced irons revolutionized the spin and control of the golf ball. These clubs allowed for greater backspin which improved the flight of the ball and control of the ball once it hits the ground. Around this time, steel shafts also became popular with golfers and improved both the accuracy of the golf shot and the durability of the golf club. 


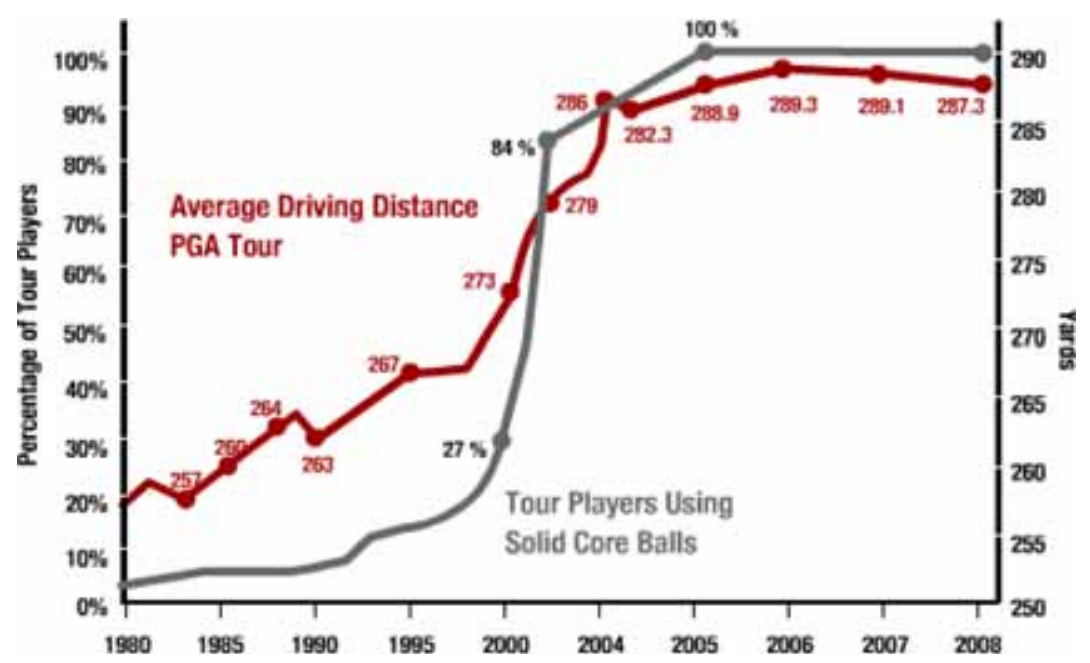

Figure 11: Correlation between percentage of tour players using solid core balls and average driving distance from 1985 to 2008 [15].

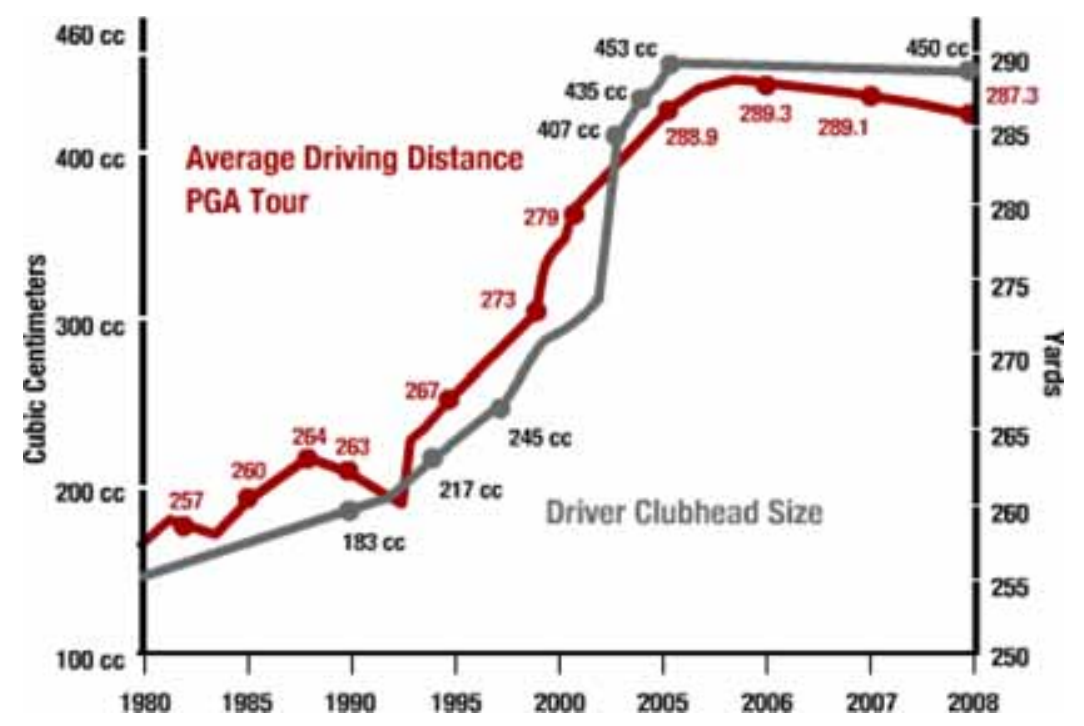

Figure 12: Correlation between driver clubhead size and average driving distance on the PGA Tour from 1980 to 2008 [15].

Another significant improvement in shaft technology was the introduction of the graphite shaft in the early 1970s. The graphite material allowed for faster swing speeds by significantly reducing the weight of the club and also made the shaft stronger [14]. Today, modern clubs are designed for distance, forgiveness, control, and consistency. Drivers have oversized (usually 420 or 460 cubic centimeters), thin-faced, titanium clubheads which offer the large 'sweet spots' and hence a more forgiving hitting area on the club face [15]. The effect that the size of these driver clubheads has had on driving distance can be seen in Fig. 12. The average driving distance on the PGA Tour has risen about 30 yards in the past 30 years, cf. Fig. 10. 
Modern irons use technologies such as cavity backs and perimeter weighting of the clubhead in order to maximize forgiveness, distance, and control. In addition to the clubhead, the shaft of the club has proven to have a significant effect on the golf shot. While light graphite shafts have increased swing speed, their flex characteristics can now be customized for specific swing speeds and desired ball trajectories in order to optimize performance [14].

\section{HOCKEY}

The evolution of the hockey stick is consistent with the evolution of the golf club, which is documented in Refs. [16-19]. Since the original hockey stick, many improvements have been made to make the stick more powerful, more accurate, and lighter. Although weight reduction is the most obvious trend, the improvements were also driven by the maximizing power and accuracy.

First, the original hockey sticks were carved out of one piece of wood. Being unable to bend much without breaking, early hockey sticks were not ideal for shooting the puck hard. By introducing the concept of laminated sticks, constructed by layering wood into a shaft and laminating it, allowed sticks to deform elastically to a much larger degree.

Another significant improvement to the hockey stick came from curving the blade. When a puck is shot, it is given linear as well as rotational momentum. By curving the blade, the stick is able to spin more consistently for two reasons. First the puck naturally wants to rest on the heel of a curved blade, and second it allows the puck to roll when taking a forward shot without the loss of linear speed. The friction along the blade is what transfers the energy for the spinning puck, so often hockey players will wrap their blades with friction tape to increase how much the puck spins and thus their consistency.

In terms of weight reduction, the limiting factor is yielding. Hockey sticks breaking can be tolerated, but players expect their sticks to last for a few games at a minimum. Composite shafts are able to handle more stress before plastic deformation. This gives manufacturers the freedom to design the internal shaft structure, to cut back on the volume of material required and the weight of the stick. Furthermore, shaft designers have been experimenting with external shape as well. Bubble heel, flex point, and kick stick shafts are features that decrease the weight of the shaft by eliminating excessive material through external shaping. This is a much more difficult problem than designing the shaft as a simple beam with uniform cross-section.

\section{BOXING}

In the evolution of the sports discussed until now, pattern coexists with randomness. The pattern is exhibited by averaged measurements, and the randomness is due to the individual example. In boxing, in each weight class, some boxers seem to have a natural ability to hit harder than their colleagues. These fighters are usually described as heavy-handed, but no reason is ever given as to why; with all their training, they have the advantage of hitting harder than their opponents. Some have it, others do not. In this section we shed light on this phenomenon, the relation between punching power and body dimensions.

There are 17 weight classes in boxing. Here we consider five: heavyweight (201 lbm \& above), light heavyweight $(175 \mathrm{lbm})$, middleweight $(160 \mathrm{lbm})$, welterweight $(147 \mathrm{lbm})$, and lightweight $(135 \mathrm{lbm})$. Using ESPN's top ten rankings for each weight class, we collected data for 50 boxers (Table 2). The data cover five quantitative aspects of the sport: height (inches), reach (inches), knockout rate (wins by KO divided by total fights), total wins, and nation of origin.

Figures 13 and 14 show the effect of reach and height on knockout rate. There is a definite upward trend in both figures, and it favors the bigger athletes. This trend can be expected to be more evident if the data pool is expanded to include more boxers, as the top ten in each weight class, particularly the lower ones, can be expected to record more knockouts than their counterparts. 
Table 2: Measurements of leading boxers [20-24].

\begin{tabular}{|c|c|c|c|c|c|}
\hline Boxer Name & Height & Reach & Knockout rate & Wins & Nationality \\
\hline \multicolumn{6}{|l|}{ Heavyweights } \\
\hline Wladimir Klitschko & 78 & 81 & $84.48 \%$ & 55 & Ukraine \\
\hline Vitali Klitschko & 79 & 80 & $88.64 \%$ & 42 & Ukraine \\
\hline David Haye & 75 & 78 & $88.46 \%$ & 25 & UK \\
\hline Tomasz Adamek & 73.5 & 75 & $62.22 \%$ & 44 & Russia \\
\hline Alexander Povetkin & 74 & 75 & $71.43 \%$ & 21 & Poland \\
\hline Ruslan Chagaev & 73 & 74 & $58.62 \%$ & 27 & Uzbekistan \\
\hline Tony Thompson & 77 & 81.5 & $62.16 \%$ & 35 & USA \\
\hline Eddie Chambers & 73 & 75 & $47.37 \%$ & 36 & USA \\
\hline Alexander Dimetrienko & 79 & 83 & $65.63 \%$ & 31 & Ukraine \\
\hline Cristobal Arreola & 76 & 78 & $81.25 \%$ & 30 & USA \\
\hline \multicolumn{6}{|l|}{ Light heavyweights } \\
\hline Jean Pascal & 70.5 & 72 & $57.14 \%$ & 26 & Canada \\
\hline Bernard Hopkins & 73 & 75 & $54.24 \%$ & 51 & USA \\
\hline Tavoris Cloud & 70 & 71 & $81.82 \%$ & 22 & USA \\
\hline Chad Dawson & 73 & 76.5 & $54.84 \%$ & 29 & USA \\
\hline Zsolt Erdei & 70 & 72 & $53.13 \%$ & 32 & Hungary \\
\hline Adrian Diaconu & 69 & 72 & $51.72 \%$ & 27 & Canada \\
\hline Gabriel Campillo & 74 & 76 & $29.17 \%$ & 20 & Spain \\
\hline Nathan Cleverly & 73.5 & 74 & $47.62 \%$ & 21 & UK \\
\hline Beibut Shumenov & 74 & 74 & $58.33 \%$ & 11 & Kazakhstan \\
\hline Jurgen Brahmer & 71.5 & 72 & $76.32 \%$ & 36 & Germany \\
\hline \multicolumn{6}{|l|}{ Middleweights } \\
\hline Sergio Martinez & 70 & 73 & $50.98 \%$ & 47 & Argentina \\
\hline Kelly Pavlik & 74 & 75 & $84.21 \%$ & 36 & USA \\
\hline Felix Sturm & 71.5 & 71 & $39.47 \%$ & 35 & Germany \\
\hline Paul Williams & 73 & 82 & $65.85 \%$ & 39 & USA \\
\hline Sebastian Sylvester & 67.5 & 68 & $42.11 \%$ & 34 & Germany \\
\hline Daniel Geale & 70 & 71 & $60.00 \%$ & 24 & Australia \\
\hline Sebastian Zbik & 71.5 & 71 & $33.33 \%$ & 30 & Germany \\
\hline Matthew Macklin & 71 & 72 & $63.33 \%$ & 28 & UK \\
\hline Dmitri Pirog & 69 & 70 & $77.78 \%$ & 18 & Russia \\
\hline Andy Lee & 74 & 76 & $73.08 \%$ & 25 & Ireland \\
\hline \multicolumn{6}{|l|}{ Welterweights } \\
\hline Floyd Mayweather & 68 & 72 & $60.98 \%$ & 41 & USA \\
\hline Manny Pacquiao & 66.5 & 67 & $66.67 \%$ & 52 & Philippines \\
\hline Andre Berto & 68.5 & 72 & $77.78 \%$ & 27 & USA \\
\hline
\end{tabular}




\begin{tabular}{llccll}
\hline Boxer Name & Height & Reach & Knockout rate & Wins & Nationality \\
\hline Welterweights & & & & & \\
\hline Shane Mosley & 69 & 74 & $72.22 \%$ & 46 & USA \\
Jan Zaveck & 67.5 & 68 & $54.55 \%$ & 31 & Slovenia \\
Joshua Clottey & 68 & 70 & $50.00 \%$ & 35 & Ghana \\
Selcuk Aydin & 67 & 67 & $75.00 \%$ & 20 & Turkey \\
Vyacheslav Senchenko & 70 & 73 & $64.52 \%$ & 31 & Ukraine \\
Kell Brook & 69 & 72 & $69.57 \%$ & 23 & UK \\
Sebastian Lujan & 66 & 68 & $52.27 \%$ & 36 & Argentina \\
\hline Lightweights & & & & & \\
\hline Juan Manuel Marquez & 67 & 67 & $65.52 \%$ & 52 & Mexico \\
Humberto Soto & 67.5 & 70 & $49.23 \%$ & 55 & Mexico \\
Brandon Rios & 68 & 68 & $71.43 \%$ & 27 & USA \\
Robert Guerrero & 68 & 70 & $56.25 \%$ & 28 & USA \\
Miguel Vazquez & 70 & 70 & $38.71 \%$ & 28 & Mexico \\
Michael Katsidis & 67 & 66 & $73.33 \%$ & 27 & Australia \\
Miguel Acosta & 67 & 70 & $64.71 \%$ & 28 & Venezuela \\
Urbano Antillon & 67 & 71 & $66.67 \%$ & 28 & Mexico \\
Antonio Demarco & 70 & 71 & $64.29 \%$ & 25 & Mexico \\
John Murray & 68 & 70 & $60.00 \%$ & 30 & UK \\
\hline
\end{tabular}

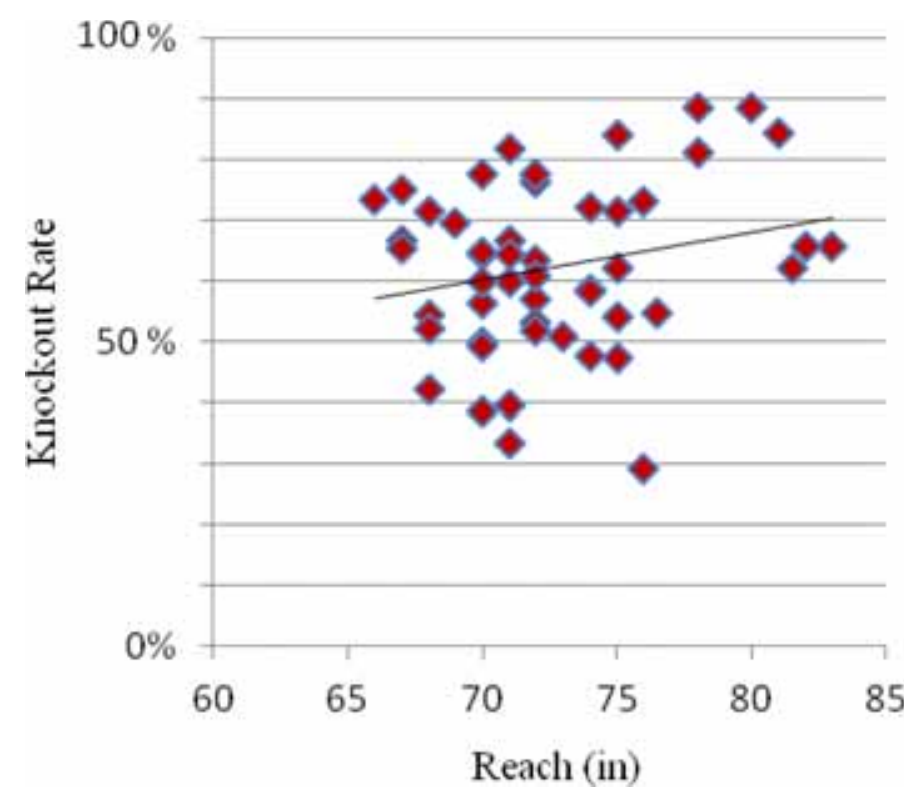

Figure 13: The effect of reach on knockout rate. 


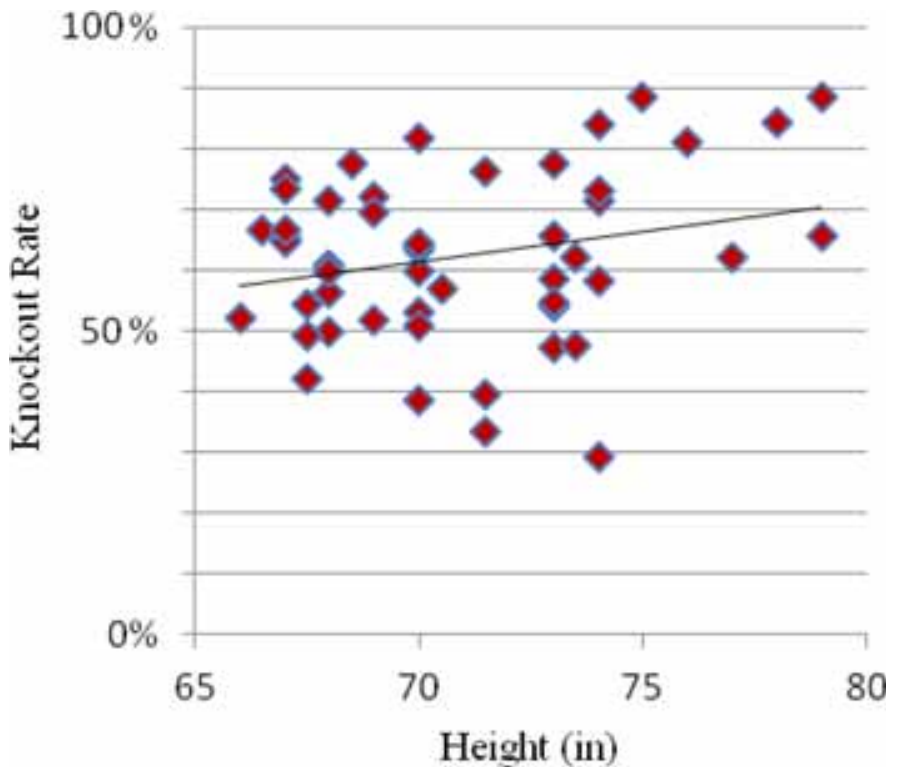

Figure 14: The effect of height on knockout rate.

Table 3: The evolution of boxing performance [20-24].

\begin{tabular}{lcccc}
\hline Welterweights & \multicolumn{5}{l}{} \\
\hline Name & Years boxed & Height & Reach & Knockout rate \\
\hline Emile Griffith & $1958-1977$ & 67.5 & 72 & $20.54 \%$ \\
Jose Napoles & $1958-1975$ & 67.5 & 72 & $61.36 \%$ \\
Kid Gavilan & $1943-1958$ & 70.5 & 71 & $19.58 \%$ \\
Ray Leonard & $1977-1997$ & 70 & 74 & $62.50 \%$ \\
Barney Ross & $1929-1938$ & 67 & 67 & $27.16 \%$ \\
Thomas Hearns & $1977-2006$ & 73 & 78 & $71.64 \%$ \\
Lightweights: & & & & \\
Freddie Welsh & $1905-1922$ & 67 & 68.5 & $20.24 \%$ \\
Henry Armstrong & $1931-1945$ & 65.5 & 67 & $56.11 \%$ \\
Carlos Ortiz & $1955-1972$ & 67 & 70 & $42.86 \%$ \\
Tony Canzoneri & $1925-1939$ & 64 & 65 & $25.14 \%$ \\
Pernell Whitaker & $1984-2001$ & 66 & 69 & $46.96 \%$ \\
Ike Williams & $1940-1955$ & 69 & 68 & $38.85 \%$ \\
Joe Gans & $1893-1909$ & 66.5 & 71 & $50.26 \%$ \\
Benny Leonard & $1911-1932$ & 65 & 69 & $32.11 \%$ \\
Roberto Duran & $1968-2001$ & 67 & 66 & $58.82 \%$ \\
\hline
\end{tabular}


Size is not all that goes into a punch. Boxing is considerably more complicated than this. Weight classes limit each boxer's ability to increase his size and power. While height and reach help fighters score knockouts, a fighter cannot become too tall and lanky and lose core strength, as power comes from more than just the arms. It comes from the entire body that falls forward, as in all throwing motions.

The key to achieving power is to maximize performance in each weight class. To see how boxers are achieving this, we examined two weight classes: lightweight and welterweight (Table 3). Looking at lists compiled of the 25 greatest fighters in each respective class, we were able to compare their sizes and knockout rates. Over time, body sizes and knockout rates have increased. Size is a major factor in achieving knockouts. Boxers have been working to maximize their body's punching power by gaining size without exceeding the weight limit. They have done this by adding muscle and length and cutting out water weight before the fight. This allows a boxer to weigh in under the limit and come into the fight with a weight advantage over their opponent. Over time, techniques for cutting weight and training specifically for boxing have improved, providing an explanation for the improvement over time in boxer's size and knockout rates.

\section{CONCLUSIONS}

In this paper we examined the evolution of four sports with throwing motion from the point of view of the constructal law of design and evolution in nature. Previously, the constructal law was used to explain why the speed sports (sprint, swimming) evolve toward larger winning athletes as the record speeds increase over time. The reason is the physics relation between body size and speed, which unites all animals and all forms of body movement (swimming, running, flying).

The throwing motion falls under the predictive tent of the constructal law, which predicts greater throwing speeds from larger and taller athletes. We demonstrated this in the present paper by examining the evolution of four sports during the past century: baseball, golf, hockey and boxing. In each, the evolution has been toward greater size and toward technological improvements that increase speed (e.g. golf clubs, hockey sticks).

Most revealing is the evolution of a team sport such as baseball, in which specialized players fill designated positions on the field, in such a way that the need for speed is distributed nonuniformly over the team sport. We found that in spite of this diversity in the design of the team sport, the evolution toward greater throwing speed from larger athletes is true, and it is commensurate with the need for throwing speed according to field position.

In summary, this paper shows that the constructal-law theory of sports evolution predicts and unites not only speed running and speed swimming $[9,10]$ but also the sports where speed is needed for throwing a mass, ball or fist. The sports of baseball, golf, hockey and boxing bring both the team and the individual throwing sports under the predictive reach of the constructal theory of sports evolution.

\section{ACKNOWLEDGMENT}

This study was performed during the course "Constructal Theory and Design", developed at Duke University with support from the National Science Foundation.

\section{REFERENCES}

[1] Bejan, A., Advanced Engineering Thermodynamics, 2nd ed., Wiley: New York, 1997, chapter 13.

[2] Bejan, A. \& Lorente, S., The constructal law and the evolution of design in nature. Phys. Life Rev, 8: pp. 209-240, 2011. doi: http://dx.doi.org/10.1016/j.plrev.2011.05.010

[3] Bejan, A. \& Zane, J.P., Design in Nature. How the Constructal Law Governs Evolution in Biology, Physics, Technology and Social Organization, Doubleday: New York, 2012. 
[4] Lorenzini, G. \& Biserni, C., The Constructal Law: from design in nature to social dynamics and wealth as physics. Phys. Life Rev, 8, pp. 159-160, 2011. doi: http://dx.doi.org/10.1016/ j.plrev.2011.08.002

[5] Lorenzini, G., Biserni, C. \& Rocha, L.A.O., Geometric optimization of isothermal cavities according to Bejan's theory. Int. J. Heat Mass Transfer, 54, pp. 3868-3873, 2011. doi: http:// dx.doi.org/10.1016/j.ijheatmasstransfer.2011.04.042

[6] Bejan, A. \& Marden, J.H., Unifying constructal theory for scale effects in running, swimming and flying. J. Exp. Biol, 209, pp. 238-248, 2006. doi: http://dx.doi.org/10.1242/jeb.01974

[7] Bejan, A. \& Marden, J.H., The constructal unification of biological and geophysical design. Phys. Life Rev, 6, pp. 85-102, 2006. doi: http://dx.doi.org/10.1016/j.plrev.2008.12.002

[8] Lorente, S. \& Bejan, A., Few large and many small: hierarchy in movement on Earth, Int J Design Nature Ecodyn, 5: pp. 254-267, 2010. doi: http://dx.doi.org/10.2495/DNE-V5-N3-254-267

[9] Charles, J.D. \& Bejan, A., The evolution of speed, size and shape in modern athletics. J Exp Biol, 212, pp. 2419-2425, 2009. doi: http://dx.doi.org/10.1242/jeb.031161

[10] Bejan, A., Jones, E.C. \& Charles, J.D., The evolution of speed in athletics: why the fastest runners are black and swimmers white. Int J Design Nature Ecodyn, 5(3), pp. 199-211, 2010. doi: http://dx.doi.org/10.2495/DNE-V5-N3-199-211

[11] Top Gun List - Fastest MLB Pitchers for the 2009 Season, available at http://www.efastball. com/baseball/stats/2009/fastest-pitchers-in-the-major-leagues-2009-season/, (accessed 13 April 2011).

[12] Team Rosters Index, available at http://www.usatoday.com/sports/baseball/rosters.htm, (accessed 13 April 2011).

[13] available at www.PGATour.com.

[14] “Golf Club History." Golf Club Revue, available at http://www.golf-club-revue.com/golf-clubhistory.html, 2009.

[15] Technology and Tradition: Preserving the Balance. Titleist, available at http://www.titleist. com/technologyandtradition, 7 July 2009.

[16] available at http://www.nhl.com/ice/page.htm?id=67157\#Results

[17] available at http://www.ecs.umass.edu/mie/labs/mda/fea/fealib/obrien/obrienReport.pdf

[18] available at http://www.thephysicsofhockey.com/documents/curve.pdf

[19] Hache, A., The Physics of Hockey, The Johns Hopkins University Press: Baltimore, MD, 2002.

[20] available at http://boxrec.com/search.php

[21] available at http://www.boxingscene.com/-top-25-welterweights-all-time-top-ten-23544

[22] available at http://www.boxingscene.com/-top-25-lightweights-all-time-top-ten-22968

[23] available at http://sports.espn.go.com/sports/boxing/columns/story?columnist=rafael_dan\& id $=3911650$

[24] available at http://www.expertboxing.com/boxing-training/punching-techniques/64-how-topunch-harder 